\title{
Practice and conceptions: communicating mathematics in the workplace
}

\author{
Leigh N. Wood
}

Published online: 8 July 2011

C) The Author(s) 2011. This article is published with open access at Springerlink.com

\begin{abstract}
The study examined the experience of communication in the workplace for mathematics graduates with a view to enriching university curriculum. I broaden the work of Burton and Morgan (2000), who investigated the discourse practices of academic mathematicians to examine the discourse used by new mathematics graduates in industry and their perceptions of how they acquired these skills. I describe the different levels of perception of discourse needs and of how they gained the necessary skills. At the lowest level, they learnt through trying out different approaches. At the next level, they were assisted by colleagues or outside situations. At the highest level, a small group viewed communication and interpersonal skills as a scientific process and stood back and used their "mathematical" observation skills to model their behaviour. These graduates did not appear to have systematically studied communication as part of their degree and they were unaware of the power of language choices in the workplace. Those who were working as mathematicians had to come to grips with explaining mathematical concepts to a wide range of people with varying mathematical skills but who generally were considerably less skilled in mathematics. The study revealed that these graduates were seriously underprepared in many aspects for joining the workforce. Many found it difficult to adapt to dealing with colleagues and managers, and developing communication skills was often a matter of trial and error.
\end{abstract}

Keywords Graduates · Mathematical communication · Phenomenography · Professional preparation $\cdot$ Workplace-related mathematics

\section{Introduction}

We interpret reality through language, according to the discourse analysts. In my case, I interpret the world through the lens of mathematical discourse. For most of my academic career, I have been fortunate enough to be engaged as a mathematician, communicating 
mathematics to other mathematicians and to students who have been exposed to the discourse of mathematics through their schooling. There are those, however, who qualify as mathematicians from university without any specific training in communication skills, but then find themselves going out into the world and needing to communicate mathematical concepts with people who have not been as widely exposed to mathematical discourse. How do they fare? Very little attention has been focused on the reality of functioning within the workplace from a learning and teaching perspective. Research on employment from the graduates' perspective is another neglected area (Johnston, 2003).

Most of the reported research about mathematics and language comes from mathematicians (mostly academics) writing within the discipline of mathematics, that is, they are writing about communicating mathematics within an area of discourse where the rules have already been established. This scenario essentially presumes that communication is with other mathematicians. The teaching and learning of tertiary mathematics is set within a similar framework, where although the mathematics may be communicated across disciplines-such as to engineering students - a commonality of both mathematical understanding and mathematical language is assumed on the basis of prior studies. However, in the non-academic workplace mathematics graduates are generally communicating mathematical concepts to nonmathematicians; even where the recipients may have received mathematical training, it is at a considerably lower level than that achieved by mathematics graduates.

Discussions about mathematical discourse are also founded on a conscious assessment of language. In general, however, mathematical language is absorbed by secondary and tertiary students by doing mathematics, since it is rare to find instances where training in communications has been an intrinsic part of mathematical learning. It is presupposed that by learning the mathematics, students will also learn the discourse; and then will automatically be able to communicate mathematical ideas to a wider public.

From the point of view of an organisation, an employee who can communicate well with others makes a more significant contribution to that organisation. Employers see communication skills as the most important graduate capability (Hoyles, Wolf, Kent, \& Molyneux-Hodgson, 2002). From the perspective of the individual, the power of language choices can help you get a job, adapt to the job and progress in a career (Burton, 2004).

I set out to investigate the forms of discourse that mathematics graduates find themselves using in the workplace and what indeed are their conceptions of mathematical discourse. And since my own context is that of an educator, I address the question: do graduates recall explicit learning or teaching of the mathematical communication they need for their employment?

\section{Language and mathematics}

\subsection{Mathematical discourse}

In this paper, I use the phrase mathematical discourse to refer to the uses of language in university mathematics learning and teaching and in professional life. Discourse is a broader concept than language because it also involves all the activities and practices that make up mathematics as a profession, such as through textbooks, computer packages, and through application of mathematical knowledge. Mathematical discourse is distinct from other types of discourse simply because mathematics is quite distinct from other subjects or disciplines and the things that mathematicians do are distinct from what other academics and professionals do: each discipline requires specific elements and styles of communication. 
Naturally, there are variations of the form depending on the mathematical and communication skills of the presenter and the receiver, but certain features distinguish mathematics discourse from other forms. For instance, it is often highly symbolic and incorporates graphic representations as well, as summed up by Hammill (2010) who looked at research on interactions between text and symbols. She also addresses the role of graphic representation and notes that: "Symbolic expressions need to be created to model real world problems and then graphs constructed from the symbolic models" (p. 1). Mathematical discourse differs from natural language in other ways such as the following: it is more economical, it encapsulates concepts in a way that clarifies connections, and it is easier to manipulate mathematical objects using their own syntax.

Mathematical symbolic language is not universal and unchanging, that is, it has been invented and developed by mathematicians to do a particular job. It could be argued that the converse is also true: that the development of the symbolic language has influenced mathematical thinking. The relationship between discourse and conceptualisation is a twoway street with each relying on the other. O'Halloran (2005) is one of the recent theorists who have been pursuing the connections between symbolism and visual images (or graphic representations) and thinking in the development of mathematical ideas, and who leads us into the ever-expanding territory of computer representation.

It is important to note, nonetheless, that the use of symbolic language has its limitations. It is easier to follow if it is expressed in ways that follow the conventions of natural language and, moreover, it is usually framed within explanatory text. A mathematician uses natural language to help other people — whether mathematicians or non-mathematicians - to understand their mathematical thinking. What we find is that mathematicians mix symbolic language with English (or another language) in different proportions and in different ways depending on what they think their audience will be comfortable with. Thus, an expert in analysis, for example, may use a greater proportion of symbolic language to communicate with a similar kind of expert than he or she would with a mathematician whose field is statistics. The real skill comes in attempting to convey mathematical concepts in predominantly natural language without losing the integrity of the mathematics.

\subsection{Examining mathematical discourse}

More recently, partly as a result of the development of a general interest in the analysis of discourse (for example, Jørgensen and Phillips (2002) give a good coverage of different approaches to discourse analysis), researchers have been teasing out how mathematical discourse works. A groundbreaking study of mathematical communication (at secondary level) was done by Morgan (1998) in Britain. Her discussion of the differences between the experience of students and professional mathematicians highlights the variation in forms of mathematical discourse:

On the whole, students have worked only on relatively short, routine problems for which little elaboration or explanation is required...In contrast, "real" mathematicians tend to work on relatively substantial and often original problems. Their anticipated audiences are expected to be genuinely interested in knowing the results and to need to be persuaded of the correctness of the results. (Morgan, 1998, p. 2)

The point is made that it is the representation of the mathematics to others that is problematic.

A group of French mathematics educators, exemplified by Duval (1999, 2001), have extended this work. Duval argues that we can gain access to mathematical objects only 
through their representations. This idea has led to a research school that investigates the ways that students develop their mathematical understandings with different representations. Durand-Guerrier (2004) sheds light on the fact that details in mathematical discourse can lead to deep misunderstanding in students; how much more problematic IS IT then for explanations to non-mathematicians.

Gestures can perform a role here in face-to-face mathematical discourse, and this has been receiving some recent attention; for instance, see the special issue of Educational Studies in Mathematics on this subject ("Gestures and Multimodality in the Construction of Mathematical Meaning", 2009, vol. 70, no. 2). Thus mathematicians -in common with any other human engaging in face-to-face discourse-will use gesture to enhance the meaning of what we are trying to convey. Sfard (2009) suggests in this special issue that the wave of interest in gestures across many disciplines has arisen in part because of developments in technology (such as modes of recording and analysing), but she also recommends caution as it is essential "to make a clear distinction between the roles of speech and that of gesturing in constituting and sustaining mathematical discourse" (p. 192).

At the professional level, Burton and Morgan (2000) examined the ways that academic mathematicians write. They argue that writing plays a critical role in many mathematical practices and that guidance in the formation of these texts is essential: "knowledge of the forms of language that are highly valued within mathematical discourses and the effects that may be achieved by various linguistic choices... would empower them," to make choices, to break conventions and express their own personality (p. 431).

Bill Barton in The Language of Mathematics (2008) also explores the intersections between language and mathematics and gives an overview of how the two are intertwined. He concludes that:

Mathematics is created by communicating, that is, mathematics is created in the act of communication...mathematics is both enabled and restricted by the conventions of communication. (p. 173)

And that:

Learning mathematics, and doing mathematics, involves talking mathematics: the more we talk mathematics, the better we will learn it and do it. (p. 174)

If we support the premises of these authors that mathematics is developed and learnt through communication and talking, why is the explicit learning and teaching of mathematical communication skills so thin in mathematics curricula? How does a mathematician trained in the use of symbols then explain the mathematics to someone who has not been so trained? This question has received little attention. Beyond the arena of the academic mathematician, the main focus of research has been into the use of mathematics in the workplace (or the need for greater application of mathematical skills) and employers' expectations of graduates (such as Selden \& Selden, 2001; Hoyles et al., 2002). Kent, Hoyles, Noss and Guile (2004) have been doing a study of the needs of industry and they found an increase in the requirement for mathematical literacy amongst employees and for skills of mathematical communication in the workforce. However, this is a rare mention of communication skills and it was raised in a minor way regarding potential problems: "The manager's model (assuming he/ she has a technical/engineering background) will tend to be based on formal mathematical models; the operator's model is far more based on the physical experience of production ..." (p. 8). 


\subsection{Language and curriculum}

A major influence on the development of language and discourse initiatives in curriculum design has been the work in systemic functional analysis theory and practice (for instance Halliday $(1985,1991))$. There are two main aims fundamental to integrating language and disciplinary studies that have been used to develop curriculum. The first is exemplified by such articles as Building Bridges: Using Science as a Tool to Teach Reading and Writing (Nixon \& Akerson, 2002), where science and mathematics are used as a vehicle to teach language. The second is where language is used to teach the mathematics/science, for example Reading and Writing to Learn Science (Glynn \& Muth, 1994). These articles are at primary and secondary school levels respectively.

These efforts have been concentrated on the interaction between language and learning science in general. While Burton and Morgan (2000) quote some published guidelines for the development of mathematical writing, they conclude that "the training of mathematicians does not appear to include any systematic attention to the development of writing skills" (p. 448). Pimm and Wagner (2003), in a review of Morgan's book (1998), emphasised the importance of analysing mathematical discourse and then teaching it effectively, since:

...lack of explicit attention to form and its crucial function in shaping successful communication leaves students to wallow in their own limitations, unable to partake of the cultural traditions into which they are (hopefully) being inculcated through their schooling. (p. 161)

Morgan (1998) suggests there has been insufficient attention paid to the divergence between the experience of language by students and professional mathematicians within curriculum design at university, with the major focus being on difficulties children may have with mathematical language (p. 3). In a similar vein, Durand-Guerrier (2004) argues that the detailed use of language has not been seriously addressed in mathematics education and in Sweden, Österholm (2005) has concluded that there is a "need for explicit teaching of reading symbolic texts, that is, more direct practice is needed for the development of the more content-specific literacy skills" (p. 342).

Despite the research into discourse, little is known about how mathematics graduates integrate their knowledge of mathematical discourse into a non-academic workplace and how they learn to communicate mathematical concepts to colleagues and clients.

This study addresses the questions:

- How do mathematics graduates use discourse to communicate mathematical ideas with a range of audiences?

- What is their intention (implicit or explicit) in the communication?

- How do graduates learn to communicate mathematical ideas?

\section{Research design}

\subsection{The methodology}

The 18 participants in the study were recruited from advertisements sent to graduates with mathematics majors who had finished their studies in the past 5 years. They had a range of 
employment situations, age, ethnicity, and academic backgrounds. The participants had graduated from five universities and had a range of degrees. Most of the participants were in their early to mid-20s. There were ten males and eight females; eight spoke languages other than English as their home language. The commonality between them is that they all regarded themselves as qualified mathematicians. Their majors and job descriptions are listed in Table 1. It should be noted that all names have been changed and ethics approval was obtained.

The participants were interviewed using a semistructured protocol for about $1 \mathrm{~h}$ each, with the aim of drawing out as full a description of their experiences as possible. The interview can be described as being in three parts. Firstly, were descriptive questions (degree awarded, major studies, age, language background), then an analysis of their work situation, and finally participants were asked to reflect on their learning. After general information on their background, each participant was asked to describe the work they do and the way mathematics is used in that work. I did all the interviews and was able to probe the participant to find the level and type of mathematics used. Participants produced work samples where applicable to show the mathematics used. I then moved to analytical questions, where graduates first described how they used mathematics to communicate and then analysed the differences between mathematics and other forms of communication. Participants reflected on their learning of communication and the transition process from university. The questions are listed in Table 2.

The semistructured interview process requires the interviewer to create empathy, to listen, to seek clarification (perhaps by restatement) and to persist by probing to elucidate shared meaning. Here is an example of a discussion with David to find shared meaning for the word "transparent".

Table 1 Description of participants

\begin{tabular}{lllll}
\hline ID & Sex & Majors & Job description & Work area \\
\hline Angie & F & Maths, finance & Loan advisor & Banking \\
Boris & M & Pure, applied & Cryptographer & Security research \\
Christine & F & Pure, applied & Police officer & Police \\
David & M & Maths, finance & Dealer bank treasury & Banking \\
Evan & M & Maths, finance & IT & Banking \\
Fredrik & M & Maths, physics & Technical officer & Hospital research \\
Gavin & M & Applied & Climate modelling & University \\
Heloise & F & Stats, OR & Logistics analyst & Industrial \\
James & M & Maths, finance & Corporate treasury & Insurance \\
Kay & F & Statistics & Statistician, tutor & University \\
Leah & F & Statistics & Clerk & Government \\
Melanie & F & Applied & Musician & Entertainment \\
Nathan & M & Applied, IT & IT development & Self-employed, industry \\
Paul & M & Maths, finance & Trading risk management & Banking \\
Roger & M & Pure, applied & Modeller, programmer & Geological surveying \\
Sally & F & Statistics & Statistician & Insurance \\
Thi & F & Engineering, maths & Loan support & Self-employed, bank services \\
William & M & Actuarial & Instructional designer & University \\
\hline
\end{tabular}

OR Operations research, IT Information technology 
Table 2 Interview questions

1. How would you describe the work that you do? In what ways do you use mathematics in this?

2. In what ways do you use mathematics to communicate ideas? Examples for prompting if necessary: reading graphs, using formulas in Excel. From others? Produced by you?

3. Is mathematical communication different to other forms of communication?

4. How did you learn these communication skills?

5. In what way has studying mathematics at university level prepared you for work?

6. What else helped you to make the transition to professional work?

7. What do you think should be in a university course to help you to make the transition to professional work?

D: ...And plus it's very transparent. Something like that is very transparent and it's very readily and easily explainable. Anything that cannot be readily explained and anything that's not transparent is not well accepted by management.

I: Transparent: define what you mean.

D: Transparent. It's just like doing a weighted average, that's very transparent because you can very easily, very, very easily see what it means. You put numbers on paper and very easily show somebody in a very easy example as to how the whole process works. Quite honestly coming up with some of the stuff, I mean some of the stuff is readily available on Excel, [...] just descriptive statistics, they're not well understood by people. People, they just can't, they can't visualise it, they need to be able to visualise it to understand it.

I: So transparent is kind of like if you are able to explain something that your manager understands, that's transparent.

D: That's right. And he's an intelligent man, but his background's not quantitative, but he's quite comfortable with quantitative ideas. But I don't think I'd be able to take him to the $[\ldots]$ calculus, that's not his cup of tea.

The circumstances of the interviews were diverse. There were graduates who had moved from their mathematics degrees into other fields of study. They could answer questions only in general, whereas those using extensive mathematics in their profession needed to be probed differently. Here are three examples of questioning for different circumstances. Firstly, asking Paul about the use of graphs for mathematical communication.

I: What about graphs?

P: No. In the most recent role at the [...] bank, there was a plan that [if] you ever handed across numbers it's only ever graphs basically because you can't sell, people, if they are not maths literate, want to see a picture. [However] doing structured finance, never did any graphs. Where I am, very occasionally if I want to pretty up a report or if it's going to say, Treasury's level or something, then yeah, but apart from that, no.

I: But you don't use graphs at all now because people understand the maths?

P: Well people are more interested in the numbers than anything else.

Here is an example talking to Thi about the use of graphs. Because she sells financial services (mainly loans), we were discussing how she communicates with her clients: 
I: O.K. And what about graphs, do you show them graphs?

T: We have the ability to show them graphs because there's a lot of online material that you can use that is already available on bank sites and any other finance sites. It shows their payments on how it is reduced, and, if you pay this much per month this is how you can reduce your payments and this is the amount of money that you can save by the end of 30 years or 25 years.

I: And how do they find that?

T: How do they find that? They like the graphical representation more than the...just the numerical.

Whereas someone such as Leah would be insulted if you asked how she uses graphs in her work:

I: Alright. So in what ways do you use your maths or stats or ...?

L: Bugger all!

Many participants also provided samples of texts they had used and/or produced in the workplace. These texts as well as the transcriptions of the interviews were examined for a factual analysis of the range of communication skills used by the graduates, which is presented below in Section 4.1. The transcribed interviews were further analysed using the phenomenographic paradigm (Marton, 1994; Marton \& Booth, 1997; Akerlind, 2005; Prosser, 2000), based on illuminating the different ways that they used and learnt mathematical discourse skills note that for the purposes of a phenomenographic study, 1520 interviews are sufficient (Kvale, 1996).

\subsection{Phenomenographic method}

Phenomenography is a well-established method for qualitative research in higher education. Ferenc Marton is one of the founding fathers (see, for example, Marton, 1994; Marton \& Booth, 1997) and others have further developed and applied the method (such as Prosser, 2000; Akerlind, 2005). It involves looking at how people experience, understand and ascribe meaning to a specific situation or phenomenon, with the aim of bringing out the range of experiences rather than the numbers of people who had those experiences. It is used to define aspects that are critically different within a group involved in the same situation, through a comparative, iterative process. The data as a whole (in this case, interviews) are interrogated for commonalities, while maintaining qualitative difference between the emerging categories. This is an iterative process, in that the researcher keeps returning to the data and refining the themes until satisfied that there is internal rigour. Marton (1994) sums up the process as follows:

Distinctly different ways of experiencing the phenomenon discussed in the interview are the units of analysis and not the single individuals. The categories of description corresponding to those differing understandings and the logical relations that can be established between them constitute the main results of a phenomenographic study. (p. 4424)

The outcome of a phenomenographic study is often a hierarchical set of logically related categories, from the narrowest and most limited to the broadest and most inclusive. This is referred to as the outcome space for the research - the categories sit within this space and attain meaning in reference to each other and to the whole set of data. 
The starting point is thus the identification of common themes expressed by participants, which are then grouped into categories through iteration. This may be done by manual coding of segments of text, or using an appropriate software programme. I used NVivo ${ }^{\circledR}$ software for the initial coding and then combed through the transcripts several times, reassessing the original themes and critical differences between them.

Many themes emerged about the nature of mathematical work done by these graduates and their difficulty in finding appropriate employment. There were themes around their transition to professional work and the kinds of learning that would enhance their transition. Graduates also reflected on what was missing in their undergraduate education. In this article, I am reporting on the main finding, which was the complexity of mathematical communication with non-mathematicians in the transition to work.

I coded the transcripts based on the themes that emerged from the data, then looked for overarching patterns. I applied this technique for both the conceptions of communication, and how they learnt mathematical discourse. This revealed a clear hierarchy in the data, that is, participants who demonstrated higher levels in the outcome space also mentioned lower levels of the hierarchy, whereas the opposite did not occur. By the end of this process I had established an identifiable set of categories of the reported experiences, with internal consistency and clear differentiation between the categories. I found they did constitute a hierarchy, wherein the higher order categories incorporated lower-order ones with the whole forming a cohesive outcome space. In the case of conceptions of professional communication, the hierarchical levels constituted jargon and notation (the lowest level), concepts and thinking (medium), and strength (the highest level). For example, those participants who described using mathematical discourse at the highest level also described the need to avoid technical terms, whereas for several participants their only stated form of mathematical discourse was to avoid technical terms (the lowest level).

The results are described in Sections 4.2 and 4.3. This description includes what graduates do (action) and why they have selected that action (intention) and demonstrates a hierarchical set of responses to workplace situations. The outcome space includes excerpts from the interviews to illuminate the categories. The quotes are as the participants have spoken, with some deletion of hesitations and other repetitions. Spoken English is full of grammatical errors and these have not been corrected. Quotes have been shortened and sections that are not relevant to the particular context have been omitted; these are shown by the use of an ellipsis (...). At all times, care has been taken not to change the sense of what a participant is saying.

\section{Results}

\subsection{Mathematical discourse practices}

In this section, I describe the discourse practices engaged in by the graduates in their professional work and the purpose (intention) in undertaking the discourse. The macro skills of discourse are reading, writing, listening and speaking; these are tested separately in language tests such as the International English Language Testing System, which is used in Australia and elsewhere for English proficiency on entering university. In undergraduate mathematics study, the skills of reading and listening are emphasised so, although I looked at the full range of discourse skills, a summarised version is presented here, focusing on particular features of speaking and writing within the context of the graduates' work situations. 
The results of the phenomenographic analysis of the participants' conceptions of communication are presented in Section 4.2. This includes what they do (action) and why they have selected that action (intention). Finally, in Section 4.3, I discuss the ways in which the graduates perceived they had learnt discourse skills.

\subsubsection{Speaking}

Presenting seminars In these situations, there is an exchange of mathematical ideas where the graduates are combining the skills of listening and speaking within a semi-formal structure. In the following quote from Boris, the group has been given an article to discuss, so reading skills are implied. Also of interest in the following quote is the reliance on the whiteboard in mathematical discussions:

Boris: Somebody just said, I want to talk about something, and you have an article or something that you hand it out beforehand...And you just go over talk... and we talk about what we don't understand, and how it affects you. But otherwise...I can always stand up, go to somebody['s] office and start talking about the mathematical ideas when we write on the whiteboard basically.

Talking with colleagues and management Oral communication within the workplace was a feature commonly raised and many had clearly worked out their own approach to these informal discussions, especially with non-mathematicians. Paul developed the following method to modify his discourse when working with non-technical colleagues:

Paul: I have a hard time explaining things without being technical ... I think that the majority of ideas, if you sit there and think, "how would I explain this (and this is how I think about it) to my brother", then usually if you can work out how to explain it then it will work with my work colleagues.

Roger gives a clear description of how he modifies his discourse for mathematicians as against non-mathematicians:

Roger: Well, fortunately there [at my workplace] both of the bosses were $\mathrm{PhDs}$ in maths themselves so they understood. So you could just leave everything in the mathematical form, you didn't have to first interpret it back into some hand-waving thing...If we had to give reports to the non-mathematical people, then we would use, we would do examples, we would have our, all our own equations in the background but then we would [give] certain examples...

Negotiating and selling ideas Part of Roger's position is to negotiate with small companies for work and here he discusses the difficulty of tendering. This quote exemplifies the situation where the audience may have some mathematical background but where it is well below that of the mathematician. It also highlights the emphasis on natural language in the workplace:

Roger: Oh, well, you must explain to them in general terms, again you have, you cannot explain it mathematically to them, that is not the point. You have to... somehow convince them that you are capable of doing this...because to them mathematics consists of arithmetic, maybe there's an equation with an $x$ in it that must 
be solved, but that's about as far as,...everything they have done which is school maths, which is nothing in comparison with even third year mathematics.

Paul is talking about communicating ideas to management and how he has to "sell" these ideas rather than simply produce a proof, as he would have done in the case of a mathematical audience:

Paul: In both my previous roles...everyone else was finance, accounting something along those lines, and weren't maths literate so if I came up with ideas or something like that I'd have to dumb down the way I was explaining it... You've got to actually sell the idea as an idea.

\subsubsection{Writing}

Informal writing While speaking and formal writing formed a large part of their communication, participants also mentioned informal writing; for example, I'll just reword and then it might be a matter of just getting on to the whiteboard [Heloise]. This is an instance of informal writing, but the whiteboard was an essential component of communication. Informal writing is a powerful element of mathematical communication. Graphs, often demonstrated on computer, are also a part of informal writing used to communicate with colleagues and clients who are mathematically less skilled.

Formal writing A more formal style of writing is necessary for reports, writing tenders, responding to tenders and producing academic articles or theses. These graduates may have had experience at school and university with some forms of formal writing, but they still experience difficulties in this area, for example in writing reports for a boss, for a client, or for management. James expresses the need to develop his formal writing skills and has been struggling with how to address the necessity for accuracy while making the ideas accessible. He has worked out a way to present information without too much detail:

James: Actually I try, it's a hard balance to be honest. For example I wrote a paper on the stability of the portfolio of deposits that we have and it's pure stats as far as standard deviation $99 \%$ and $95 \%$ confidence intervals, for a report paper for example. So I'm using the maths in that but I wouldn't give them the spreadsheet with all the formulas on it. I'd just say "using data back for the last 18 months I can be $99 \%$ confident that the portfolio won't be more than 3 or 5 million dollars in a day"...you have got to get the information there but you don't kill them with the detail. So I do use the stats to get the results but then how much of that do I use to explain the result? It depends on the audience.

\subsection{Conceptions of professional communication}

\subsubsection{Levels of conception}

Participants described how they use mathematical communication, but what is the essential variation that makes one description (experience) different from another? Using the 
phenomenographic paradigm to address this question and illuminate the outcome space, I discuss their responses within the context of each person's entire transcript. I found that this outcome space primarily relates to the participants' conceptions of discourse when dealing with non-mathematicians.

Analysis of the data resulted in three ordered categories of graduates' conceptions of mathematical communication with level 3 being the highest level and inclusive of the lower categories.

Level 1: jargon and notation Mathematical discourse is about using technical vocabulary and symbols, but when participants at this level explain mathematics to non-mathematicians they try to avoid such vocabulary. People who hold this conception see the components of the texts as being the barrier to communication; therefore to communicate it necessitates changing the vocabulary and perhaps the semiotic representation by using a picture or a graph. Their belief is that it is the words and images of the discourse that are hindering the communication and that removal, or simplification, will fix this. This is different from talking with mathematicians where changing the vocabulary is not necessary, and equations, for instance, can be used. To illustrate:

Thi: Talking to colleagues we can go into a more technical discussion about our field and they'll understand the lingo. Predominantly, it's the lingo... whereas if I was to start an in-depth conversation with a client, I'd have to explain to them what every word meant first.

Level 2: concepts and thinking Rather than simply eliminating mathematical vocabulary and symbols, when some graduates at this level explain mathematics to non-mathematicians they instinctively "dumb down" the ideas; others endeavour to present a careful exposition of the ideas to their colleagues or clients. They believe that the different thinking acquired by mathematics training makes it impossible to communicate mathematical ideas to those who have not been so trained. This is where some participants express frustration with their inability to negotiate meaning:

Melanie: You've somehow got to convey to somebody who thinks that maths is just a couple of numbers and equations maybe, and a tick or a cross, like something's right or wrong...it's kind of trying to get over that hurdle and say, OK well the maths that you know about isn't actually what maths is.

Level 3: strength Mathematical discourse is about the potency of mathematical knowledge and the ability to communicate it. Those who hold this conception strive to present correct mathematics and put forward objective arguments, rather than just translating mathematical concepts for an untrained audience. They realise that they have powerful mathematical knowledge and proficiency, but also that they must be able to communicate it, otherwise their strength is useless. They recognise that the power of mathematics brings ethical responsibilities. The mathematics person in an organisation has to be able to make arguments that are justified and will help management (or others) make informed decisions:

James: You can do a bullet-proof argument without being subjective, you can just quote the facts...For example if you work in a bank if you look at the issues right at the moment that are around its losses, if you have someone who is an expert in that field, they are going to be a maths person no doubt, I'm sure everyone in 
management is asking, "what's going on here?". You need to be able to communicate in general and in jargon.

\subsubsection{Actions and intentions}

If graduates hold these different conceptions of mathematical discourse, how do they respond in the workplace? The graduates suggested that it depends on whether their audience has a mathematical background. Table 3 summarises the responses from the participants for communication with non-mathematicians. Notice that because the levels are hierarchical, participants who espouse any specific conception talk about lower actions and intentions as well. When communicating with those who have a mathematical background, the conceptions hold but the actions and intentions are different.

There is a qualitative difference between levels 1 and 2 in both intention and action, and again between levels 2 and 3 (Table 3). For the two lower level conceptions (levels 1 and 2), some participants were in a work situation where it was important for their colleagues to understand the mathematical details even though the participants modified their use of words and, perhaps, simplified the ideas. For the highest-level conception, no participants required their audience to understand the mathematical details. They had confidence in their own mathematical knowledge and their ability to communicate it meaningfully in their workplace.

Table 3 Intention and action towards non-mathematicians

\begin{tabular}{|c|c|c|}
\hline Conception & Intention & Action \\
\hline \multirow[t]{3}{*}{ 1. Jargon/notation } & A. To be more efficient and friendly & $\begin{array}{l}\text { A. Omit technical terms and } \\
\text { equations }\end{array}$ \\
\hline & B. To avoid losing the audience & $\begin{array}{l}\text { B. Omit technical terms and } \\
\text { equations }\end{array}$ \\
\hline & $\begin{array}{l}\text { C. To simplify the language to help } \\
\text { the audience to understand }\end{array}$ & $\begin{array}{l}\text { C. Avoid technical terms and } \\
\text { repeat yourself in different } \\
\text { ways - observing the } \\
\text { response of your audience }\end{array}$ \\
\hline \multirow[t]{5}{*}{ 2. Concepts/thinking } & $\begin{array}{l}\text { A. Don't explain-the audience will } \\
\text { never understand }\end{array}$ & $\begin{array}{l}\text { A. Do nothing-it is too difficult } \\
\text { to explain mathematical thinking }\end{array}$ \\
\hline & $\begin{array}{l}\text { B. To give an impression of a mathematical } \\
\text { concept - the audience will never } \\
\text { understand the real idea }\end{array}$ & $\begin{array}{l}\text { B. Dumb down ideas, use "hand } \\
\text { waving" and pictures }\end{array}$ \\
\hline & C. For the audience to understand & $\begin{array}{l}\text { C. Careful exposition of ideas, } \\
\text { explaining in different ways, } \\
\text { teaching }\end{array}$ \\
\hline & $\begin{array}{l}\text { D. To give only an impression of a } \\
\text { mathematical concept-the audience } \\
\text { does not want and/or need to understand }\end{array}$ & $\begin{array}{l}\text { D. Careful discourse to give an } \\
\text { overview without detail }\end{array}$ \\
\hline & $\begin{array}{l}\text { E. To win a contract or an argument- the } \\
\text { audience cannot or does not need to } \\
\text { understand details }\end{array}$ & $\begin{array}{l}\text { E. Be inspiring and sell ideas } \\
\text { instead of explaining }\end{array}$ \\
\hline 3. Strength & $\begin{array}{l}\text { Justify the mathematics in an appropriate } \\
\text { context so that the audience will understand } \\
\text { the consequences of the mathematics. } \\
\text { Present ideas ethically and correctly }\end{array}$ & $\begin{array}{l}\text { Use mathematics and mathematical } \\
\text { discourse in a flexible way, as the } \\
\text { situation requires. Check for } \\
\text { accuracy and correctness }\end{array}$ \\
\hline
\end{tabular}


They did not expect their audience to understand the mathematics, but recognised that their audience needed to be able to use the mathematical knowledge.

\subsection{Learning discourse}

Just as I interrogated the data to tease out graduates' conceptions of communication (Section 4.2) using phenomenographic methods, I also analysed the interview transcripts using the same process for their conceptions of how they had learnt mathematical discourse. I found that participants expressed three levels of understanding of how they learnt mathematical discourse, with the key qualitative difference being the level of control that the graduate exercised. The first level is one where trial and error is used to work out the right communication technique for the situation. For the second level, graduates learnt communication skills from an outside source, for example from their bosses, or an outside agency such as a church group or sporting organisation. On the third level, graduates stood back, systematically observed good and bad communication, and actively modelled good practice. None of the graduates believed they had learned communication skills as part of their studies; in fact more than one graduate made a comment like: Those sort of people skills I do not think, one certainly cannot learn them at the maths department! [Roger].

In this section, I have again used quotes to illustrate the outcome space.

Level 1: go with the flow, trial and error Some developed their skills through trial and error, for instance: It's usually that glaze-over effect! When they start glazing over it's time to stop! [Evan]. Heloise is working in a medium-sized company where she and her boss are the "quants". The interview showed that she is not in control; she exemplifies the process of making it up as she goes along by mirroring the language used by those around her:

Interviewer: So, how did you learn to talk differently to different people?

Heloise: I don't know. I just kind of picked it up. Mainly I'd respond by the way they spoke to me. If they speak analytically to me... with my manager...So, I know that I can speak like that to him, type thing...

Level 2: mediated by others and outside situations People with these experiences have worked with a supervisor or within an outside influence, such as a church group, where there has been active direction by an external source about how to communicate in an appropriate style. Here, there has been clear interaction in terms of how ideas can be expressed, with a consequent modification by the graduates of their communication style:

Paul: Experience. After, when you first come out of uni[versity] and you try to explain ... and you run it past your boss, who says it is way too technical, take all the technical stuff out of it and just give them what they can understand, write for the audience. If you hear that and get told that often enough, then sooner or later, it changes the way that you deal with people at work.

Level 3: active, detached observation The graduates who express these experiences have generally approached communication in the workplace in a scientific way and have closely observed the good and bad ways that interaction occurs, then modified their behaviour accordingly. They have not relied on trial and error but have observed rigorously and made controlled, conscious decisions about how to communicate: 
Roger: There were two kinds that stood out. Firstly those that stood out in a positive way, and those that stood out in a negative way! So then the ones that stood out in a negative way, they were exactly the sorts of people you would expect to come out of the maths department almost, very dry and techy....and then on the other hand the interesting people had a different style, you know, they spoke about interesting things...even in the context of their work, they'd always try to approach it from the more general perspective...Yeah, it was quite a learning curve I must say.

These levels are hierarchical: those with level 3 responses also used trial and error (level 1) and outside influences (level 2), and those whose experiences were mediated by others (level 2) also used trial and error. The difference between these levels is one of control. At level 3, the graduates are exercising control of their environment by using observational skills, making their own judgments and then modifying their behaviour. At level 2, the graduates are being directly moderated by their boss or outside influences; at level 1, the graduates are not in any position of control and are merely reacting to each situation in which they find themselves by using simple coping mechanisms. The participants who demonstrated a level 3 conception of learning to communicate were using critical language awareness (Jørgensen \& Phillips, 2002), by observing the discourse practices of the workplace and modifying their behaviour in a much more detached and scientific way from those who used trial and error - this is what differentiates this level from the two below. It is notable that the participants believed they learnt their skills once leaving university.

In terms of the links between conceptions of mathematical discourse and learning the discourse, those who considered that mathematical discourse is jargon tended to have learnt their communication skills by trial and error or by mirroring those around them. All participants modified their use of jargon when dealing with non-mathematicians, but those with higher level conceptions used other strategies as well to enhance their communication.

\section{Discussion}

These graduates have come to define themselves as "mathematicians"; they see their work and life in terms of mathematics even if they are not working as mathematicians. All exhibit sophisticated conceptions of mathematics. They have assimilated their learning experiences at university and these have changed their way of looking at the world, then their jobs have given them a wider perspective again.

The study revealed that these graduates were seriously under-prepared in terms of communication skills for joining the workforce. Although all participants who used mathematics in their employment were in positions where they had to communicate mathematics to non-mathematicians, they were generally unaware of language choices and how to communicate at different levels. An interesting aspect of their difficulties was the degree to which they raised problems with oral communication and interpersonal skills. Many of the mathematicians were working alone within their area of expertise and had to adjust to the language of those around them-with no training for this from university.

Participants saw mathematics communication as:

- jargon/notation

- concepts/thinking

- strength 
Of these, the strength conception was the most inclusive, and jargon (or notation) the least inclusive. When explaining mathematics to non-mathematicians, the first-level strategy is to take out the technical jargon or notation. They next tried to make the concepts more accessible to lay people. One participant described how he imagined his brother as the audience when discussing mathematical ideas in his workplace. (Is this a compliment to his brother? I think not.) Other participants described how different the way of thinking is for those trained in mathematics, and the difficulty of explaining the concepts to others. Those who could explain clearly had gained greater control and strength in the workplace. There was a qualitative difference between each level with the most marked difference being between levels 2 and 3 .

None had learnt mathematical communication as part of their undergraduate study. How they learnt communication skills occurred at three levels of experience:

- go with the flow, trial and error

- mediated by others and outside situations, and

- active, detached observation

While not directly asked, several participants commented on the consequences of poor communication skills in the workplace, not only for themselves but also for the whole organisation. They also talked about the potential for personal problems with advancement if they were unable to adequately express details of their work practices with colleagues and managers.

There are implications for curriculum development worth considering here. I believe, as implied by Morgan (1998), that an appropriate course of action is to investigate how practising mathematicians use mathematical discourse, and develop teaching and learning strategies on this basis to induct students into the discourse of the discipline. A one-off subject, however, is not likely to be sufficient to develop the full range of the discourse skills required. Mathematical discourse needs to be taught explicitly, not just within the context of mathematics as a discipline, but also in the context of enabling students to interact with a wider audience (some techniques are presented in Wood and Petocz (2003) and in Wood and Smith (2007)). It is, after all, ultimately the responsibility of speakers to tailor their communication to their audience.

There is a real need for curriculum reform to help our students with adjustment to the workforce, so that we do not squander people who have technical skills but lack the necessary communication and interpersonal skills. Better mathematical communication will open more employment for mathematicians as employers become more aware of the power of mathematics in their organisations.

Acknowledgements Many thanks to the graduates who participated. Thank you to Anna Reid and Glyn Mather for their input into the study.

Open Access This article is distributed under the terms of the Creative Commons Attribution Noncommercial License which permits any noncommercial use, distribution, and reproduction in any medium, provided the original author(s) and source are credited.

\section{References}

Akerlind, G. (2005). Learning about phenomenography: Interviewing, data analysis and the qualitative research paradigm. In J. A. Bowden \& P. Green (Eds.), Doing developmental phenomenography (pp. 6374). Melbourne, Australia: RMIT University Press.

Barton, B. (2008). The language of mathematics: Telling tales. New York: Springer.

Burton, L. (2004). Mathematicians as enquirers: Learning about learning mathematics. Dordrecht: Kluwer. Burton, L., \& Morgan, C. (2000). Mathematicians writing. Journal for Research in Mathematics Education, 31(4), 429-453. 
Durand-Guerrier, V. (2004). Surreptitious changes in letters' status in mathematical discourse: A source of difficulties in understanding, elaborating and controlling demonstration. In Proceedings of International Congress on Mathematics Education, ICME10, Copenhagen, July 4-11. http://www.icme-organisers.dk/ tsg25/. Accessed 20 October 2007

Duval, R. (1999). Representation, vision and visualisation: Cognitive functions in mathematical thinking. In F. Hitt \& M. Santos (Eds.), Proceedings of the 21st Annual Meeting North American Chapter of the International Group of PME (pp. 3-26). México: PME.

Duval, R. (2001). The cognitive analysis of problems of comprehension in the learning of mathematics. Psychology of Mathematics Education, 25. http://www.math.uncc.edu/ sae/dg3/duval.pdf. Accessed 20 April 2005

Glynn, S. M., \& Muth, K. D. (1994). Reading and writing to learn science: Achieving scientific literacy. Journal of Research in Science Teaching, 31(9), 1057-1073.

Halliday, M. A. K. (1985). Spoken and written language. Geelong, Australia: Deakin University.

Halliday, M. A. K. (1991). Writing science: Literacy and discursive power. London: The Falmer Press.

Hammill, L. (2010). The interplay of text, symbols, and graphics in mathematics education. Transformative Dialogues: Teaching \& Learning Journal, 3(3). http://kwantlen.ca/TD/TD.3.3/TD.3.3 Hammill Mathematics_Education.pdf. Accessed 9 July 2010

Hoyles, C., Wolf, A., Kent, P., \& Molyneux-Hodgson, S. (2002). Mathematical skills in the workplace. http:// www.ioe.ac.uk/tlrp/technomaths/skills2002/. Accessed 22 August 2006

Johnston, B. (2003). The shape of research in the field of higher education and graduate employment: Some issues. Studies in Higher Education, 28(4), 414-426.

Jørgensen, M., \& Phillips, L. (2002). Discourse analysis as theory and method. London: SAGE Publications.

Kent, P., Hoyles, C., Noss, R., \& Guile, D. (2004). Techno-mathematical literacies in workplace activity. International seminar on learning and technology at work, Institute of Education, London. http://www. lkl.ac.uk/kscope/ltw/seminar2004/Kent-LTW-seminar-paper.pdf. Accessed 22 December 2006

Kvale, S. (1996). Interviews: An introduction to qualitative research interviewing. California: Sage Publishing.

Marton, F. (1994). Phenomenography. In T. Hus'en, \& T. N. Postlethwaite (Eds.) The international encyclopedia of education, 2nd ed., vol. 8 (pp. 4424-4429). Oxford: Pergamon.

Marton, F., \& Booth, S. (1997). Learning and awareness. New Jersey: Lawrence Erlbaum.

Morgan, C. (1998). Mathematicians writing: The discourse of investigation. London: Falmer.

Nixon, D.T., \& Akerson, V.L. (2002). Building bridges: Using science as a tool to teach reading and writing. In Proceedings of the Annual International Conference of the Association for the Education of Teachers in Science (pp. 1-26).

O’Halloran, K. (2005). Mathematical discourse: Language, symbolism and visual images. London: Continuum.

Österholm, M. (2005). Characterizing reading comprehension of mathematical texts. Educational Studies in Mathematics, 63, 325-346.

Pimm, D., \& Wagner, D. (2003). Investigation, mathematics education and genre: An essay review of Candia Morgan's Writing mathematically: The discourse of investigation. Educational Studies in Mathematics, $53,159-178$.

Prosser, M. (2000). Using phenomenographic research methodology in the context of research in teaching and learning. In J. A. Bowden \& E. Walsh (Eds.), Phenomenography (pp. 24-32). Melbourne: RMIT University Press.

Selden, A., \& Selden, J. (2001). Examining how mathematics is used in the workplace. Mathematics Association of America. http://www.maa.org/t_and_1/sampler/rs_6.html. Accessed 3 October 2007

Sfard, A. (2009). What's all the fuss about gestures? A commentary. Educational Studies in Mathematics, 70 (2), 191-200.

Wood, L. N., \& Petocz, P. (2003). Reading statistics. Sydney: University of Technology, Sydney.

Wood, L. N., \& Smith, N. F. (2007). Graduate attributes: Teaching as learning. International Journal of Mathematical Education in Science and Technology, 38(6), 715-727. 